\title{
Sistema cultural de creencias religiosas. Un estado de la cuestión*
}

\author{
JOHANNA EMILCE CORTÉS DAZA**
}

Recepción: 12 de enero de 2019

Aprobación: 10 de junio de 2019

Forma de citar este artículo: Cortés, J. E. (2019). Sistema cultural de creencias religiosas. Un estado de la cuestión. Cuadernos de Lingüística Hispánica, (34), pp 21-40.

doi https://doi.org/ 10.19053/0121053X.n34.2019.9898

* Artículo de reflexión

** Magíster en Lingüística de la Universidad Pedagógica y Tecnológica de Colombia. Labora en la Escuela Normal Superior Sor Josefa del Castillo y Guevara de Chiquinquirá. Becaria actual de Colciencias y estudiante de Doctorado en Lenguaje y Cultura de la Universidad Pedagógica y Tecnológica de Colombia. Correo electrónico: johanna.corts@gmail.com (iD https://orcid. org/0000-0001-5595-3720 


\section{Resumen}

En este artículo de revisión se lleva a cabo una investigación documental de carácter cualitativo, cuyo objetivo primordial es establecer un estado de la cuestión sobre la temática de los sistemas culturales de creencias religiosas. Para ello se trazó una ruta metodológica que tuvo en cuenta cuatro momentos: revisión documental; clasificación de los estudios en investigaciones académicas, libros de investigación y artículos científicos; categorización; y posterior análisis, interpretación y valoración de los enfoques teóricos y metodológicos. En los resultados se puede entrever que existe un campo investigativo prácticamente inexplorado, que debe ser valorado a través de nuevas investigaciones.

Palabras clave: religiosidad, creencias, sistema cultural de creencias religiosas, identidad, fiestas religiosas.

\section{Cultural System of Religious Beliefs. State of the Art}

\section{Abstract}

In this review, a documentary research of a qualitative nature is carried out, whose main objective is to establish a state of the art on the subject of cultural systems of religious beliefs. For this, a methodological route was drawn up that took into account four moments: documentary review; classification of studies in academic research, research books and scientific articles; categorization; and subsequent analysis, interpretation and evaluation of the theoretical and methodological approaches. As results, it can be seen that there is a virtually unexplored field of research that must be valued through new research.

Keywords: religiousness, beliefs, cultural system of religious beliefs, identity, religious holidays.

\section{Système culturel de croyances religieuses. Un état de la question}

\section{Résumé}

Dans cet article de révision on mène à bien une recherche documentaire de type qualitatif, dont l'objectif primordial est celui d'établir un état de la question sur la thématique des systèmes culturels de croyances religieuses. Pour cela, on a défini une voie méthodologique qui tient compte de quatre moments : révision documentaire; classements des études en recherches académiques, livres de recherche et articles scientifiques; catégorisation et analyse ultérieure; interprétation et mise en valeur des approches théoriques et méthodologiques. Dans les résultats, on peut entrevoir qu'il existe un do- 
maine de recherche pratiquement inexploré, qui doit être valorisé à travers de nouvelles recherches.

Mots clés: religiosité, croyances, système culturel de croyances religieuses, identité, fêtes religieuses.

\section{Sistema cultural de crenças religiosas. Um estado da questão}

\section{Resumo}

Neste artigo de revisão, é realizada uma investigação documental qualitativa, cujo objetivo principal é estabelecer um estado da questão sobre o tema dos sistemas culturais de crenças religiosas. Para isso, traçou-se um roteiro metodológico que levou em consideração quatro momentos: revisão documental; classificação de estudos em pesquisa acadêmica, livros de pesquisa e artigos científicos; categorização; e posterior análise, interpretação e avaliação de abordagens teóricas e metodológicas. Os resultados mostram que existe um campo de pesquisa praticamente inexplorado, que deve ser avaliado por meio de novas pesquisas.

Palavras-chave: religiosidade, crenças, sistema cultural de crenças religiosas, identidade, feriados religiosos.

\section{Introducción}

Este artículo de revisión sirve como base para estatuir un estado de la cuestión que hace parte de la tesis doctoral denominada "Sistema cultural de creencias religiosas en Chiquinquirá", dentro del programa de formación posgraduada, Doctorado en Lenguaje y Cultura. Se sitúa dentro de la línea de investigación Lenguaje, Sociedad y Cultura. La temática de este estudio se centra en los imaginarios sobre la religiosidad popular, desde una perspectiva sociológico-antropológica en el municipio de Chiquinquirá, Boyacá, Colombia.

En distintos lugares del mundo, los estudios sociales del lenguaje han dado cuenta de las múltiples dimensiones que tienen ciertos fenómenos culturales (Fairclough, 2008). Una de las situaciones investigativas temáticas que ofrece variedad de posibilidades de análisis es el sistema cultural de las creencias religiosas, pues la fe, la experiencia religiosa, los ritos, la relación entre lo sagrado y lo profano, las teorías que analizan el fenómeno religioso, entre otros, tienen un valor preponderante (Giberson, \& Artigas, 2007). 
Desde esa línea de disertación, existe el interés investigativo de descifrar el significado, las oportunidades de construcción teórica y metodológica de un estudio que informe de los trabajos más importantes sobre el tema de este artículo. Los métodos, los modelos, las pautas y los discursos implican, metodológicamente, una construcción de sentido, de forma cualitativa de carácter documental, de modo que se da una visión del estudio del fenómeno religioso con un énfasis interpretativo.

\section{Metodología}

Este trabajo se realizó con base en una ruta metodológica de la investigación. El paradigma que se tuvo en cuenta es cualitativo de tipo interpretativo. El tipo de investigación es documental y fue relevante en la medida en que se exploraron diferentes instrumentos y técnicas de investigación, soportadas en las condiciones contextuales de los diferentes estudios analizados (Williams, 1999). Los materiales, los insumos y la aplicación de los aspectos metódicos tienen valor en la medida en que dieron razón de las múltiples formas de abordar las investigaciones (Jäger, 2003).

Este trabajo se basa en un enfoque de carácter cualitativo, que a veces es referido como investigación naturalista, fenomenológica, interpretativa o etnográfica, y que es una especie de "paraguas" en el cual se incluye una variedad de concepciones, porque su característica más profunda es que aunque no se prueban hipótesis, estas se generan durante el proceso y van refinándose conforme se recaban más datos (Hernández, Fernández \& Baptista, 2006).

El tipo de investigación es de carácter documental, pues se sustenta en una técnica que permite la recopilación de información para enunciar las teorías que sustentan el estudio de los fenómenos y procesos en un determinado ámbito del saber (Smith, s.f.). La recopilación y organización sistemática de la información abre nuevas puertas a enigmas, alternativas y clarificación de la información sobre un campo científico.

Como muestra del estado de la cuestión, los documentos para revisar fueron seleccionados bajo criterios de conveniencia: investigaciones académicas, publicaciones editoriales (libros) de investigación (Smith, s.f.). Con base en la muestra, el primer instrumento se diseña mediante una tabla que atiende las sugerencias de Smith Avendaño y que se complementa con otros datos que se han recogido durante el proceso de muestreo. Así pues, se presenta la ruta investigativa a manera de línea de tiempo, después del análisis de los datos que se ha realizado, mediante el siguiente esquema que señala el estado actual de sistematización que se ha concretado en el acápite posterior. 


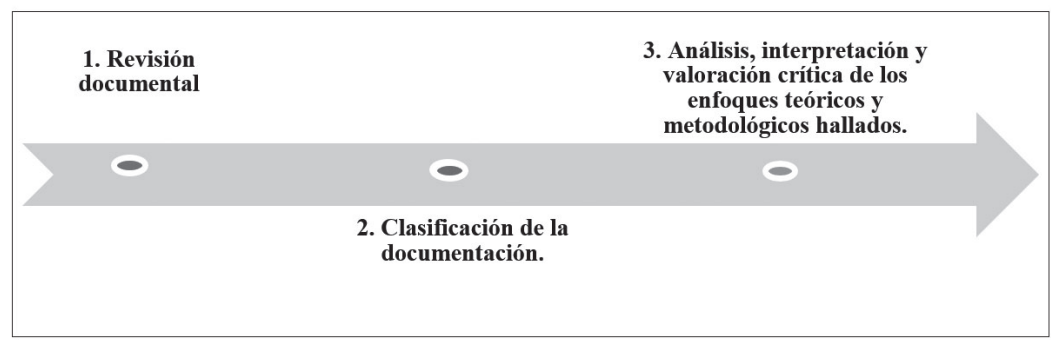

Figura 1. Ruta metodológica.

\section{Reflexiones académicas en torno al sistema cultural de creencias religiosas}

Este acápite analiza investigaciones precedentes que tienen que ver con la temática del sistema cultural de creencias religiosas populares, con base en los enfoques propios de la antropología, el análisis del discurso y la sociología del lenguaje como faros investigativos. Se reseñan y se confrontan los puntos más relevantes de varios trabajos que se articulan de diversas formas con el ámbito teórico y el esquema metodológico.

Lo anterior se proyecta a partir de la recolección de antecedentes bibliográficos en los sistemas de información científica de las diferentes unidades de análisis conformadas por libros, artículos y tesis doctorales, tomados de bases de datos científicas. Este rastreo incluye estudios que giran alrededor de la temática propuesta y algunos que se aproximan desde diversos enfoques y métodos. Estos documentos permiten constituir un panorama en sus aspectos reflexivo-teórico, metódico y analítico y como sistematización de los datos, para generar un estado de la cuestión sobre el pensamiento académico de la religión y su incidencia en el sistema cultural de las creencias religiosas.

El análisis de estas fuentes se presenta a partir de líneas temáticas identificadas, producto de la organización y sistematización de los datos, con base en los procesos de 1 y 2 de la ruta metodológica: revisión documental y clasificación de la documentación. De esta forma, las temáticas que focalizan este trabajo investigativo son: a) estudios históricos y sociales sobre religión, en los que se destacan posturas historiográficas, geográficas y de actualidad; b) la búsqueda de identidad desde el sistema cultural de creencias religiosas, en el que se privilegian credos específicos, gestualidades, actitudes y creencias, que proveen un marco de hallazgos identitarios; y c) festividades y religiosidad popular como fenómeno social, cuyos ejes de indagación giran en torno a la articulación entre medios de comunicación y religiosidad popular, el fenómeno de las imágenes y su culto 
(la representación de la Virgen, los santos y Jesús, y la muerte — vista desde la esfera de lo sagrado o santo_-, entre otros).

\subsection{Estudios históricos y sociales sobre religión}

El libro Tratado de historia de las religiones. Morfología y dinámica de lo sagrado, de Mircea Eliade (1970), es uno de los más importantes documentos para tener en cuenta, tanto en la construcción de los antecedentes de investigación, como en el esquema teórico del fenómeno religioso, puesto que abarca un sinnúmero de posibilidades de análisis histórico sobre las creencias e ideas religiosas.

Eliade define hierofanía como la manifestación de lo sagrado en el ser humano, en la esfera del cosmos habitual de los individuos. Por otra parte, se delimitan las cratofonías como las manifestaciones de fuerza de los individuos en búsqueda de lo sagrado. Según el autor, la noción de lo sagrado es opuesta a lo profano. Desde estas nociones o presupuestos, Eliade desarrolla su hipótesis inicial de trabajo en torno a las religiones y las creencias de la humanidad: es a partir de las hierofanías que el ser humano comprende la dimensión diferenciada de lo sagrado y lo profano, de modo que ciertas manifestaciones religiosas de carácter vital unen lo sagrado con el universo (Eliade, 1970).

Estas ideas constituyen un punto de partida para reflexionar el ámbito teórico de la investigación doctoral. Por un lado, permiten extrapolar un amplio recorrido histórico acerca de la religión; por otro, se pueden analizar diferencias, semejanzas y posturas en las diversas formas de recrear las creencias religiosas. De la misma manera, sirven como aporte a la estructura metodológica a la hora de entablar un diálogo analítico y reflexivo sobre la conceptualización teórico-filosófica del fenómeno religioso.

El libro titulado Regiones y religiones en México. Estudios de la transformación sociorreligiosa, de Hernández y Rivera (2011), es producto de una investigación que plantea el estudio de la diversidad religiosa en México; aborda temáticas como el análisis de las regiones y los procesos religiosos que suceden en ellas: diversificación y pluralidad de credos y religiones en estas regiones, mediados por su extensión y el papel activo de la religiosidad popular y de las creencias en la estructuración de la práctica social, con un enfoque que abarca la sociología y la antropología.

Este documento resalta a los actores sociales como protagonistas en el cambio religioso y las transformaciones que de este se derivan, visto desde y dentro de los contextos políticos, programas de instituciones religiosas y factores externos, con base en el análisis de grupos poblacionales constituidos en las diferentes zonas o regiones establecidas. 
En Antropología de lo religioso y educación, Fullat (2016) hace una revisión de diferentes momentos históricos que evalúan antropológicamente la visión de la religión como fenómeno. El estudio parte de tres preguntas inesquivables que los humanos nos formulamos, según Kant: 1) ¿qué puedo saber?; 2) ¿qué debo de hacer?; 3) ¿qué puedo esperar? Este tercer cuestionamiento abre a la religión (Fullat, 2016). Este trabajo permite la evaluación sistemática de trabajos y concepciones en el mundo occidental acerca del ámbito religioso.

En primer lugar, el autor señala que la civilización latina entendió la religión en un doble aspecto: como piedad que pone en contacto a los seres humanos con la divinidad y a modo de conjunto de prácticas rituales institucionalizadas (Fullat, 2016). En ese sentido, se puede afirmar que la religión se entiende como una delimitación de lo sagrado y lo profano y que hay una definición histórico-filosófica occidental de las creencias religiosas. El trabajo de Fullat, asimismo, establece la afinidad existente entre Freud, Nietzsche y Marx, cuya crítica radica en la comprensión de la conciencia.

Marx lleva a cabo la revisión en el plano histórico mostrando que lo consciente es simplemente ideología. Nietzsche subraya que la conciencia no es otra cosa que un efecto patológico quedando la moral reducida a genealogía. Freud en su metapsicología hace notar que la conciencia es un sistema periférico del aparato psíquico que pasa a ser síntoma y en modo alguno causa. La conciencia es mentirosa. (Fullat, 2016, p. 45)

Igualmente es importante la reflexión de Fullat (2016) sobre la comprensión religiosa desde el espacio teorético de la antropología. Para ello se vale del etnólogo Lévi-Strauss $(1964,1973)$, quien considera que las leyes inconscientes del espíritu humano fuerzan a este a imitarse a sí mismo como objeto y, por tanto, los productos culturales como la religión objetivan las condiciones inconscientes de la colectividad (Heidegger, 2005). Esto es, una nueva condición para relacionar la mismidad con la intersubjetividad. Sin embargo, es pertinente referir que el ser humano vive también de pasiones y siempre encuentra tensiones entre sus sentimientos y sus razones. La conclusión es fundamental: la religión, la política y la vida misma no escapan de esta tensión.

En el artículo, "¿Eclipse o efervescencia de lo religioso en la contemporaneidad?", de la investigadora María Eugenia Talavera, se reflexionó acerca del papel de la religión en la sociedad actual. Con fundamento en la idea de que la sociedad de la razón sustituye las creencias y que el poder de los sabios remplaza al clero, así como también con base en el planteamiento de Weber $(1981,1987,1997)$ sobre el desencantamiento del mundo, y el "politeísmo", la autora establece las características de la religiosidad actual en Caracas. 
Las conclusiones suponen que a pesar de que las proyecciones se dan sobre la percepción de que la religión se desvanecería con el peso de la razón y del avance de la modernidad en las sociedades, el panorama es diferente, ya que "se evidencia el papel relevante que ella tiene en el universo sociocultural y político de los hombres de este planeta” (Talavera, 2009).

La reflexión teórica permitió vislumbrar que la religión, en lugar de desaparecer, tiende a mutar de acuerdo con las necesidades de los creyentes, dando lugar a manifestaciones religiosas de tipo mágico-místico que incluyen adhesiones de varias religiones, creencias en esoterismos, situaciones fuera de la tierra, y la generación de cultos según lo dispongan los medios de comunicación, una religiosidad mediatizada que influye hasta en las esferas de la sociedad y la política (Zubiri, 1984). La variedad de oferta y demanda constituye lo que denomina "la globalización religiosa".

\subsection{La búsqueda de identidad desde el sistema cultural de creencias re- ligiosas}

La tesis doctoral denominada "Identidad católica y juventud universitaria en la sociedad de hoy: la identidad del católico no practicante", de García (2012), se enmarca dentro de una población de jóvenes universitarios de la Universidad de Granada, residentes en Granada. Los jóvenes se caracterizaron como católicos no practicantes en el terreno religioso, de modo que se desarrolló un estudio conducente a explorar sociológicamente las peculiaridades que conllevan la pertenencia a la religión católica en su historia personal — sin hacer uso de ciertas prácticas religiosas institucionalizadas_- la matriz social, política, cultural, familiar, escolar y eclesiástica que forma parte de vivir la fe católica de los jóvenes universitarios (Durkheim, 1982).

La metodología se construyó desde un enfoque cuantitativo y cualitativo. Para la obtención de datos estadísticos de corte cuantitativo se hicieron encuestas que permitieron determinar que el $78 \%$ de los universitarios españoles reconoce haber sido educado en la religión católica, pero solo el 45 \% afirma ser católico (García, 2012).

La investigación se fundamenta en determinar y reflejar, además, las creencias reconocidas por la población y los cambios de preferencias en la actualidad, desde miradas interdisciplinarias, incluida la sociología que desde un enfoque etnográfico, nos permite para esta investigación tener una mirada metodológica en un estudio de una comunidad geográficamente establecida. (García, 2012, p. 2012)

En lo referente a las técnicas de investigación cualitativa, se eligió el grupo de discusión, entendido como un conjunto de personas que discurren acerca de una entrevista, 
para recopilar y seleccionar la información más relevante sobre el problema por discernir. Esta técnica asume una postura de informalidad que permite complejizar de una forma colectiva las diferentes opiniones y perspectivas de los individuos del grupo, con criterios de tranquilidad, menor restricción y mayor libertad de expresión (Malinowski, 1993).

Una de las conclusiones que arrojó el estudio supone una disminución del porcentaje de arraigo católico. Según otras investigaciones revisadas por el autor, para 2006, el 63 \% de los jóvenes era católico y la mayoría se declaraba no practicante. El porcentaje de católicos es del $53.5 \%$, de los cuales el $42 \%$ manifiesta no ser practicante, para el final de la investigación. Como espacio inferencial de corte cualitativo, el autor de la tesis doctoral afirma que la ausencia de práctica religiosa ha aumentado de forma relevante en todos los tramos de edad en las últimas décadas (García, 2012).

En la investigación titulada "La corporalidad religiosa contemporánea. La gestualidad religiosa como construcción de identidad", de Avilés (2012), se plantean preguntas de investigación como: ¿Es posible reconocer las nuevas gestualidades cristianas contemporáneas que identifiquen al actor social en el ambiente religioso? ¿Cuál es el papel que juega la simbólica corporal religiosa como parte de la construcción identitaria del actor social — creyente—?, y ¿Qué herramienta metodológica nos ayuda para el análisis de la incidencia de las emociones espirituales en cuanto creación de gestualidades religiosas contemporáneas?

Otro momento del análisis en esta investigación es la gestualidad de los orantes; en ella, basados en los postulados de Le Breton (1998), se especifican los gestos simbólicos que además tienen implicatura inmediata en las palabras que dirigen en sus oraciones. Se retoma lo que se denomina como la oración del cuerpo que acompaña a la oralidad, como abrir las manos, apretar los párpados, y los denominados kinemorfemas ${ }^{3}$ que, en suma, y a manera de conclusión "jalona con sus gestos la identidad religiosa del actor social".

La investigación recoge los datos dentro de la observación participante y la historización de las gestualidades religiosas, de modo que convergen dos perspectivas: la histórica y la de la cotidianidad. A partir de este estudio se posibilita el análisis de la identidad como pertenencia e intercambio. Todo ello es analizado, a su vez, desde la sociología,

3 En los estudios kinésicos se entiende el kinema como la unidad mínima de movimiento por analizar, y los kinemorfemas, como la asociación gestual e hilada de varios kinemas. 
para determinar cómo los rezos, fiestas, procesiones, rezos a los difuntos, novenarios, devociones a los santos, pago de promesas, preparación para sacramentos, entre otros, se convierten en la vivencia antropológica de la fe.

Por otra parte, la investigación "Influencia de las creencias religiosas en las actitudes en el personal sanitario (PS) ante la muerte", de los investigadores Raja et al. (2002), tiene como objetivo analizar la influencia de las creencias religiosas en las actitudes del personal sanitario (médicos y enfermeros del hospital universitario Puerta del Mar de Cadiz) ante la muerte, partiendo de la aplicación de un diseño observacional- transversal, mediante la cual se cruzan variables de actitudes y ansiedad ante la muerte, con variables de creencias religiosas.

A partir de los instrumentos diseñados: cuestionario sociodemográfico; cuestionario STAI (A/R) (A/E) de Spilberger, para evaluar ansiedad-estado, ansiedad-rasgo; escala de ansiedad ante la muerte "DAS-1" de Templer; e inventario de creencia religiosa, se pudo concluir en el aspecto de religiosidad que el creyente confeso afirma que es poco participante en las actividades institucionales, la mujer es más creyente que el hombre, las creencias religiosas de los profesionales no influyen al trabajar de manera directa con pacientes que han muerto; sin embargo, en el personal que laboró con pacientes se evidenció desacralización.

"Actitudes, creencias y prácticas religiosas de los trabajadores en Pasto: un estudio exploratorio", de Ortega y Villamarín (2012), publicado en la Universidad del Valle, es un artículo que explora, analiza y recolecta metodológicamente información cuantitativa relativa a la comprensión del fenómeno considerado. Los diversos datos permitieron avizorar un horizonte sobre las condiciones actuales de la religiosidad local de Pasto, aunque sus autores reconocen que la investigación abre caminos para nuevas indagaciones, puesto que emergieron muchos más interrogantes que los que pudo resolver.

Como objetivo general, los autores pensaron en explorar las creencias, actitudes y prácticas religiosas de los trabajadores de la ciudad de Pasto en el año 2009 (Ortega \& Villamarín, 2012). Los autores puntualizan que es una realidad poco abordada no solo en Colombia, sino también en el ámbito internacional, lo que presupone un acuerdo con las conclusiones que esta investigación documental ha definido en el marco de la revisión bibliográfica y documental realizada hasta el momento. En el ámbito regional de Nariño se establece que:

[...] los estudios relacionados con la religión se encuentran principalmente en escritos de orden histórico, situados en los periodos de la Conquista y la Inde- 
pendencia. La dinámica de dichos estudios gana fuerza gracias al protagonismo que cobra a finales del siglo XIX, la figura de Fray Ezequiel Moreno Díaz, ícono de la mentalidad antirrevolucionaria, antimoderna y profundamente religiosa que ha estereotipado la cultura local, especialmente la de Pasto, como "teológica y conservadora”, en sus formas más extremas. (Ortega \& Villamarín, 2012, p. 263)

Como se trató de una investigación de carácter empírico, el horizonte de la misma permite tener datos que pueden ser ampliados de manera cualitativa, de modo que se plantea la posibilidad de establecer nuevos procesos de indagación, en el marco del panorama actitudinal, de creencias y prácticas religiosas del municipio de Pasto. Mediante este procedimiento, llevado a cabo a través de encuestas, se puede sopesar la posibilidad de relacionar los modos, algunas preguntas concretas y los tratamientos analíticos de esta investigación con nuevas hipótesis y premisas de trabajo. En profundidad, los autores desglosan el escenario metodológico de su trabajo.

La estrategia metodológica empleada para la recolección de la información cuantitativa es la revisión, interpretación y clasificación secundaria de estadísticas sociales provenientes de la Encuesta de Creencias y Prácticas Religiosa de la Zona Andina Nariño (ENCREPAREL 2009) del Observatorio Social del Departamento de Sociología de la Universidad de Nariño. (Ortega \& Villamarín, 2012, p. 263)

\subsection{Festividades y religiosidad popular como fenómeno social}

En el artículo "Milagros en la radio. Intersecciones entre comunicación y religiosidad popular", de la investigadora Miguel (2016), se describen los recursos mediáticos de la iglesia pentecostal para llegar a su público y realizar incluso "milagros de sanación y prosperidad", por la intercesión del radio o la televisión.

Basados en los postulados de Semán (2006) acerca de la religiosidad popular, los razonamientos de Assman (1987) caracterizan la puesta en escena de la religiosidad a través de los medios y del concepto de "iglesia electrónica" propuesto por Martín (1995). En la investigación de Assman se concluye que la iglesia pentecostal, objeto de estudio, emplea características discursivas propias que se manifiestan en el plano de religiosidad popular y, por ende, en su cultura.

En la investigación "Manifestaciones de la religiosidad popular en torno a tres imágenes marianas originarias. La unidad del ritual y la diversidad formal", de Vences (2009), se expone el análisis al culto de tres vírgenes latinoamericanas: la Virgen de Guadalupe (México), la Virgen de Chiquinquirá (Colombia) y la Virgen de El Quinche (Ecuador). A partir de una labor documental se exponen la similitud de culto, las tradi- 
ciones y la forma en que se desarrolló la devoción a estas tres imágenes tras una tradición importada de España y transmitida tras los periodos coloniales en estos territorios.

De igual forma se explica como a partir de las costumbres de cada región en que se pretendía insertar cada imagen se construyó un sincretismo que dio paso a la religiosidad popular — aceptada por la institucionalidad — propia de cada país, y el cual constituye en la actualidad las marcas de identidad de cada población. Se pudo determinar la diseminación oral de los atributos milagrosos asignados a estas imágenes, para observar que en la actualidad se mantiene el crecimiento en las poblaciones y, a su vez, el desarrollo económico, político y social.

En el documento "La Virgen de Talpa: religiosidad, turismo y sociedad", de la investigadora Fernández (2012), se expone un trabajo investigativo acerca de la religiosidad popular en torno al culto de la imagen del catolicismo. Mediante una serie de entrevistas se evidencia que Iglesia, Estado y sociedad convergen para potenciar la economía local de la mano de la evangelización.

En el artículo "Culto y festividad a San Luis Rey en la colonia El Ajusco: un testimonio de religiosidad popular en la ciudad de México”, del investigador González (2014), el propósito es indagar acerca de la construcción cultural tejida alrededor de la fiesta a este patrono mexicano, mediante entrevistas en diferentes momentos a la hija de la organizadora-fundadora de la ceremonia, desde su contexto urbano popular, siguiendo el modelo de Bourdieu (1999).

De la investigación surgen conclusiones que destacan que la relación entre la comunidad y San Luis Rey está mediada por una relación de compromisos y favores en el contexto específico del cual emerge una religiosidad popular que se recrea continuamente y que confirma los postulados de Broda (2001, 2006). Por otra parte, entre los resultados de la investigación se destaca para el caso el interrogante de Hiernaux (1977, 2006) acerca de quién es el creador de los sistemas simbólicos - los actores o aquellos que desean impartir las doctrinas_- Dado el contexto urbano de la investigación, se asume la postura de Parker (1993), quien sostiene que la presencia de los cultos de religiosidad popular en una población es coexistente con las necesidades de la población.

En el documento denominado "El culto al Señor de las Maravillas, una expresión de la religiosidad popular de tipo urbano en la ciudad de Puebla”, de Jiménez (2013), se puede observar que el fenómeno religioso está vigente, pues es un sistema de registro simbólico y ritual. El contexto en el que persiste se caracteriza por los cambios. La mayoría de estos se ubican en el universo de la tradición, pero, al mismo tiempo, intentan que 
esta no sea excluida del universo de la modernidad. De manera que la religión ha logrado permanecer bajo una nueva forma, la de la tradición en la modernidad (Hervieu-Léger, 2005).

Las comunidades construyen sus espectros divinos, sus mitos y sus creencias, que se reproducen culturalmente en medio de la tensión entre tradición y transformación de sí mismas, a partir de las necesidades cotidianas y en el marco de definidos cimientos terrenales. Esto permite observar la recurrencia de una revelación del imaginario simbólico, que permite explicar la razón de ser y el sentido de lo sagrado. Desde una perspectiva dialéctica, los fenómenos religiosos son parte del todo social estructurado y se hallan en permanente interacción y conexión internas con la realidad concreta (Báez-Jorge, 2011).

Por otra parte, la investigación denominada "Una festividad religiosa como signo de identidad, migrantes bolivianos en Jujuy”, desarrollada por Guzmán (2006), parte de la celebración en honor a la Virgen de Copacabana. Indaga la significación religiosa de la ceremonia y los agentes que participan en ella, en Jujuy, Bolivia.

La investigación, constituida desde la creación y ejecución de un fenómeno significativo, mostró las formas en que los actores sociales, tras el ritual, constituyen un mensaje presente en el espacio social de los jujeños. Así pues, comunicación, cultura e identidad convergen en este estudio que permite observar la construcción identitaria, con base en los postulados de Geertz (1987) y desde el concepto de religión aportado por Manuel Marzal (1995), quien la define como el sistema de creencias, ritos, sentimientos, formas de organización y normas éticas sobre lo divino, que generan ciertas actitudes y estados de ánimo en el individuo y sirven para dar sentido trascendente a la vida (Marzal, 1995). De esta investigación se pueden retomar aspectos teóricos y metodológicos del estudio de grupos poblacionales que dan cuenta de creencias y construcción de significados a partir de las prácticas sociales, específicamente, de las religiosas.

Por su parte, en el documento "Fiestas en honor a la santa Muerte en el Caribe mexicano", el investigador Higuera-Bonfil (2015) hace un análisis etnográfico acerca del carácter cultural de los rituales a la santa Muerte en tres ciudades diferentes de México. Estas fiestas se llevan a cabo gracias a la contribución económica y laboral de sus fieles, que para ellos representa una inversión como manifestación de la fe. Según Giménez (2013), de las tres fiestas estudiadas, dos poseen las dimensiones eclesiástico-institucional e histórica, que les permiten ser categorizadas como expresiones de la religiosidad popular. 
En "El santo quiere fiesta. Devoción, halagos y agasajo a San La Muerte, Provincia de Buenos Aires Argentina", artículo de avances de tesis doctoral de Calzato y Sánchez (2012), se analizan las fiestas en honor de San La Muerte como culto religioso y el carácter devocional del mismo con actividades como bailes, asados, procesiones, entre otras, que atienden a lo consolidado como culto católico popular.

Basados en teorías de Pieper (1974), Cox (1972) y Moltmann (1972), se plantean los festejos de santos particulares enmarcados dentro de las creencias religiosas populares, iconografía en imágenes de diferentes materiales, descripción de ofrendas y rituales con los cuales se busca la protección, el favorecimiento en diferentes peticiones, la sanación, entre otros, en los cuales además se rinde culto mariano, bajo la advocación de la Virgen de la Milagrosa, así como a otros santos.

La investigación de corte antropológico plantea la recolección de la información a través de la observación directa y la realización de entrevistas a devotos, quienes además ostentan la reconstrucción identitaria con la vestimenta de los santos en algunos de los lugares de esta investigación.

Como colofón de la investigación se determina el carácter cultural en la acción de los devotos, en relación con lo planteado por Geertz (1987): las practicas allí descritas se realizan para asegurar que el santo venerado "devore los monstruos de la incertidumbre y el caos"; las fiestas se convierten, lejos del descontrol, en espacios para que San La Muerte ejerza el restablecimiento de la existencia y la justicia en esta población que "se ajusta a un molde simbólico en el que se instala su vida”.

\section{Resultados y discusión}

Aunque no se han hecho demasiadas aportaciones sobre el conocimiento y desarrollo cultural de los estudios sociales del lenguaje en Boyacá, alrededor de estudios científicos que tengan que ver con los sistemas culturales de creencias religiosas, se afirma que la revisión documental, la clasificación, la categorización y su posterior análisis, interpretación y valoración de los enfoques teóricos y metodológicos hallados, constituye una motivación en el plano de los significados sociológicos y antropológicos que fueron interpretados (Gadamer, 2005).

Por consiguiente, si la elaboración de un estado de la cuestión contribuye al fortalecimiento de los estudios religiosos en Colombia, se puede pensar en una amplia gama de posibilidades investigativas. Por ejemplo, los principios de la Constitución Política de Colombia (1991) establecen la pluriculturalidad de la nación. Aunque existe una fuerte 
acogida de otros credos, predomina lo católico sobre los demás. Esto tiene una incidencia cultural proveniente de la conquista española y de los procesos de colonialismo. Al respecto, un estudio publicado por la revista Semana reveló lo siguiente:

El Pew Research Center, centro de investigación con sede en Washington, realizó un estudio global sobre católicos en el mundo, según el cual Colombia es el sexto país con mayor cantidad de población católica. Según ese centro de investigación, durante el 2010, el país contó con 38.100.000 católicos, ocupando así el tercer lugar en Latinoamérica, siendo superado por Brasil, que ocupa el primer lugar en el mundo con más de 126 millones de católicos y México con más de 96 millones. (Revista Semana, 2013)

Proporcionalmente, Colombia ocupa el tercer lugar en el mundo con un $82.3 \%$, solo superada por Polonia y México (Revista Semana, 2013). En ese sentido, la religiosidad emerge como una variable de estudio que tiene importancia capital en el desarrollo cultural del país y, en este caso específico, de la comprensión de un sistema cultural de creencias de comunidades.

\section{Conclusiones}

La técnica de recolección empleada corresponde en general al método documental etnográfico. Las conclusiones de las investigaciones apuntan a la consolidación de construcción de identidad y cultura en las poblaciones que participan de los fenómenos de la religiosidad, así como de las creencias que se derivan de un modo específico de sentir este tipo de experiencias. Las categorías halladas en los diferentes estudios se pueden resumir en seis módulos referidos a los rasgos de la vida religiosa, tales como filiación religiosa; religiosidad, creencias religiosas; religión y otras instituciones sociales; religión y algunas situaciones de la realidad actual; y finalmente, pluralismo y cambio religioso.

Basados en los postulados de Marzal (1995), se puede afirmar que el punto de lo festivo es un escenario fuerte por investigar, mediante la identificación de los participantes a través de símbolos como el baile, la sanación, la música y los devotos que comparten la misma trama simbólica, religiosa y cultural.

Como colofón de esta investigación documental se determina el carácter cultural en la acción de los devotos, en relación con lo planteado por Geertz (1987): las prácticas allí descritas se realizan para asegurar que el fenómeno religioso "devore los monstruos de la incertidumbre y el caos"; por otra parte, las fiestas se convierten, lejos del descontrol, en el restablecimiento de la existencia y la justicia en esta población que se ajusta a un molde simbólico en el que se instala su vida. 
El hecho de que el estudio de sistemas culturales de creencias religiosas esté en auge determinante para concebirse como una disciplina dentro de los estudios sociales del lenguaje y la cultura, permitió a este trabajo de revisión proporcionar un marco metodológico de análisis que tiene en cuenta el desarrollo de los diferentes estudios en las dimensiones teóricas anteriormente propuestas.

Con base en lo anterior, se hace necesario reconocer las tendencias teóricas y metodológicas que se han desarrollado en este contexto sociogeográfico, comprender la forma en que un sistema cultural de creencias religiosas contribuye a la comprensión de una determinada comunidad o sociedad. De la misma forma, un estado de la cuestión sobre este tema sirve para conocer las maneras en que las comunidades reflejan su carácter, sus aspectos culturales y sociales.

De acuerdo con los planteamientos de Bagú (1989), la religión es una construcción de la sociedad. Por tanto, la sociedad no solo define, sino que además crea la realidad psicológica. Es pues, el proceso cultural que da sentido de vida al individuo, que permite la cohesión social y la construcción de identidades sociales e individuales, bajo la posibilidad de comprender la tensión natural entre conservación de las tradiciones y la transformación de las mismas y de las comunidades.

En la investigación planteada se encuentra una similitud en los intereses investigativos en cuanto a cuestión de territorio, por ello uno de los interrogantes que se plantean en la investigación se asemeja a los propósitos investigativos de este estudio: ¿Qué relación tienen los campos religiosos con los grupos sociales populares? ¿Qué papel cumplen en la ciudad las recientes creencias religiosas? Estos interrogantes se asimilan a la inquietud investigativa de la religiosidad popular en la ciudad de Chiquinquirá.

Finalmente, la investigación documental invita a pensar desde las perspectivas de las prácticas religiosas a través de ciencias como la antropología cultural y la sociología, que abordan los temas religiosos en diferentes escalas de análisis, generalmente en lo local. El acercamiento a conceptos como: "campo religioso" y "secularización, como recomposición de creencias", vistos desde una complementariedad, refuerzan hipótesis dentro de la investigación en desarrollo, pues abren el espacio para lo que será el análisis del comportamiento religioso en la población de la ciudad de Chiquinquirá, a través de procesos históricos, culturales y sociales que actúan en la recomposición social de la religión. 


\section{Referencias}

Assman, H. (1987). La iglesia electrónica y su impacto en América Latina. San José: Editorial Departamento Ecuménico de Investigaciones.

Avilés, D. (2013). La corporalidad religiosa contemporánea. La gestualidad religiosa como construcción de identidad. Revista Científica Guillermo de Ockham, 10(2), 29-36.

Báez-Jorge, F. (2011). Debate en torno a lo sagrado. Religión popular y hegemonía clerical en el México Indígena. México D.F.: Biblioteca de la Universidad Veracruzana.

Bagú, S. (1989). La idea de Dios en la sociedad de los hombres. Buenos Aires: Siglo XXI.

Bourdieu, P. (1999). La miseria del mundo. (H. Pons, trad.). Madrid: Akal.

Broda, J. (2001). La etnografía de la fiesta de la Santa Cruz. En Broda \& Félix Báez (coords.), Cosmovisión, ritual e identidad de los pueblos indígenas de México (pp. 165-238). México: Fondo de Cultura Económica.

Broda, J. (2009). Religiosidad popular y cosmovisiones indigenas en la bistoria de México. México: Inah.

Calzato, W.A. \& Sánchez Hernández, G. (2012). El santo quiere fiesta. Devoción, halagos y agasajo a san la muerte, provincia de Buenos aires, Argentina. En: virajes, Antropología y sociología, Vol. 14, No. 2, pp. 255 - 273, Universidad de Caldas, Manizales.

Constitución política de Colombia (1991, 20 jul.). Texto de la Constitución. Gaceta Constitucional, (116).

Cox, H. (1972). La fiesta de locos. Salamanca: Sígueme.

Durkheim, E. (1982). Las formas elementales de la vida religiosa: el sistema totémico en Australia. Madrid: Akal.

Eliade, M. (1970). Tratado de historia de las religiones. Morfología y dinámica de lo sagrado. (A. Medinaveitia, Trad.). París: Payot.

Fairclough, N. (2008). El análisis crítico del discurso y la mercantilización del discurso público: las universidades. Discurso \& Sociedad, 2(1), 170-185.

Fernández, A. M. (2012). La Virgen de Talpa: religiosidad, turismo y sociedad. Revista Política y Cultura, (38), 29-48. Recuperado de http://www.redalyc.org/pdf/267/26725009003.pdf

Fullat, 0. (2016). Antropología de lo religioso y educación. Barcelona: Universidad de Barcelona.

Gadamer, H. G. (2005). Verdad y método I. Salamanca, España: Sígueme. 
García, E. (2012). Identidad católica y juventud universitaria en la sociedad de hoy: la identidad del católico no practicante. (Tesis doctoral). Facultad de Ciencias Políticas y Sociología, Departamento de Sociología, Universidad de Granada, Granada, España.

Geertz, C. (1987). La interpretación de las culturas. Buenos Aires: Gedisa.

Giberson, K. \& Artigas, M. (2007). El oráculo de la ciencia: celebridades científicas contra Dios y religión. Nueva York: Oxford University Press.

Giménez, G. (2013). Cultura popular y religión en el Anábuac. México: Universidad Autónoma de Aguascalientes.

González, D. (2014). Culto y festividad a San Luis Rey en la colonia El Ajusco: un testimonio de religiosidad popular en la ciudad de México. Relaciones, (139), 233-254.

Guzmán, J. (2006). Una festividad religiosa como signo de identidad, migrantes bolivianos en Jujuy. Cuadernos de la Facultad de Humanidades y Ciencias Sociales, Universidad Nacional de Jujuy, (31), 53-66. Recuperado de bttp://www.scielo.org.ar/scielo. php?script $=$ sci_arttextEpid $=$ S1668-81042006000200003Elng $=$ esEnrm $=i$ iso

Heidegger, M. (2005). Ser y tiempo. México D.F.: Fondo de Cultura Económica.

Hernández, R., Fernández, C. \& Baptista, P. (2006). Metodología de la investigación. México D.F.: Mc Graw Hill.

Hernández, A. \& Rivera, C. (2009). Regionesy religiones en México. Estudios de la transformación sociorreligiosa. México: Centro de Investigaciones y Estudios Superiores en Antropología Social, Colegio de Michoacán.

Hervieu-Léger, D. (2005). La religión, hilo de memoria. Barcelona: Herder.

Hiernaux, J. P. (1977). L'Institución Culturelle. Systematisation théorique et methodologique. (Disertación doctoral). Universidad Católica, Lovaina.

Hiernaux, J. P. (2006). Repensar la religión en un mundo en transformación. Relaciones, Zamora, Colegio de Michoacán, (108), 85-104.

Higuera-Bonfil, A. (2015, jul.-dic.). Fiestas en honor a la Santa Muerte en el Caribe mexicano. Liminar, Estudios Sociales y Humanísticos, 13(2), 96-109. Recuperado de http://www. scielo.org.mx/scielo.php?script $=$ sci_arttext\&pid $=\$ 1665-80272015000200008$

Jäger, S. (2003). Discurso y conocimiento: aspectos teóricos y metodológicos de la crítica del discurso y del análisis de dispositivos. En R. Wodak \& M. Meyer (comp.). Métodos de análisis crítico del discurso (pp. 61-100). Barcelona: Gedisa. 
Jiménez, L. A. (2013). El culto al Señor de las Maravillas, una expresión de la religiosidad popular de tipo urbano en la ciudad de Puebla. Cuicuilco, 20(57), 279-295.

Levi-Strauss, C. (1964). Lo crudo y lo cocinado. Paris: Plon.

Levi-Strauss, C. (1973). Antropología estructural. Paris: Plon.

Le Breton, D. (1998). Las pasiones ordinarias. Antropología de las emociones. Buenos Aires: Nueva Visión.

Malinowski, B. (1993). Magia, ciencia y religión. Barcelona: Planeta Agostini.

Martín, J. (1997). De los medios a las mediaciones. Comunicación, cultura y begemonía. México: Gili.

Marzal, M. (1995). Un siglo de investigación de la religión en el Perú. Anthroplogica, (14), 6-28.

Miguel, G. H. (2016). Milagros en la radio. Intersecciones entre comunicación y religiosidad popular. Revista Sociedad y Religión, (47). Recuperado de http://www.scielo.org.ar/ scielo.php?script=sci_arttext\&pid=S1853-70812017000100004

Moltmann, J. (1972). Sobre la verdad, la alegría y el juego. Salamanca: Sígueme.

Ortega, X. A. \& Villamarín, F. J. (2012). Actitudes, creencias y prácticas religiosas de los trabajadores en Pasto: un estudio exploratorio. Sociedad y Economía, (22), 261-288.

Parker, C. (1993). Otra lógica en América Latina. Religión popular y modernización en América Latina. México: Fondo de Cultura Económica.

Pieper, J. (1974). Una teoría de la fiesta. Madrid: Rialp.

Raja, H.R., Gala, L.F.J., González, I., Giménez, L. Guillén, G. C. \& Sánchez, I. A. (2002, jul.). Influencia de las creencias religiosas en las actitudes en el personal sanitario (P.S.) ante la muerte. Cuadernos de Medicina Forense, (29), 21-36. Recuperado de http://scielo.isciii. es/scielo.php?script $=$ sci_abstract\&pid $=$ \$1135-76062002000300002

Revista Semana (2013, 14 de feb.). Colombia, el sexto país con más católicos. Recuperado de http://www.semana.com/mundo/articulo/colombia-sexto-pais-mas-catolicos/333397-3

Semán, P. (2006). Bajo continuo. Exploraciones descentradas sobre cultura popular y masiva. Buenos Aires: Gorla.

Smith Avendaño, G. (s.f.). A qué nos referimos cuando bablamos de estado del arte, estado del conocimiento, estado de la cuestión y antecedentes de la investigación. Tunja: Universidad Pedagógica y Tecnológica de Colombia. 
Talavera, M. E. (2009). ¿Eclipse o efervescencia de lo religioso en la contemporaneidad? Argos, 26(51). Recuperado de http://www.scielo.org.ve/scielo.php?script $=$ sci arttext\&pid $=$ S0254-16372009000200005

Vences, M. (2009). Manifestaciones de la religiosidad popular en torno a tres imágenes marianas originarias. La unidad del ritual y la diversidad formal. Revista Latinoamérica, (49), 97126. Recuperado de http://www.redalyc.org/articulo.oa? $\mathrm{id}=64012283005$

Weber, M. (1981). Economía y sociedad. México: Fondo de Cultura Económica.

Weber, M. (1987). Ensayos sobre sociología de la religión. Madrid: Taurus.

Weber, M. (1997). Sociología de la religión. Madrid: Istmo.

Williams, R. (1999). Symbolic interactionism: the fusion of theory and research? Masachussets: Bryman y Burgess.

Zubiri, X. (1984). El hombre y Dios. Madrid: Alianza. 